\title{
PROJECTIONS OF THE AVAILABILITY AND COST OF RESIDUES FROM AGRICULTURE AND FORESTRY
}

\author{
VASSILIS DAIOGLOU ${ }^{1,2}$, ELKE STEHFEST ${ }^{2}$, BIRKA WICKE $^{1}$, ANDRE FAAIJ $^{3}$ and \\ DETLEF P. VAN VUUREN ${ }^{1,2}$ \\ ${ }^{1}$ Copernicus Institute of Sustainable Development, Utrecht University, Heidelberglaan 2, Utrecht 3584 CS, The Netherlands, \\ ${ }^{2}$ PBL Netherlands Environmental Assessment Agency, PO Box 303, Bilthoven 3720 BA, The Netherlands, ${ }^{3}$ Energy \\ Sustainability Research Institute Groningen (ESRIG), University of Groningen, Blauwborgje 6, PO Box 221, Groningen 9700 \\ $A E$, The Netherlands
}

\begin{abstract}
By-products of agricultural and forestry processes, known as residues, may act as a primary source of renewable energy. Studies assessing the availability of this resource offer little insight on the drivers and constraints of the available potential as well as the associated costs and how these may vary across scenarios. This study projects long-term global supply curves of the available potential using consistent scenarios of agriculture and forestry production, livestock production and fuel use from the spatially explicit integrated assessment model IMAGE. In the projections, residue production is related to agricultural and forestry production and intensification, and the limiting effect of ecological and alternative uses of residues are accounted for. Depending on the scenario, theoretical potential is projected to increase from approximately $120 \mathrm{EJ} \mathrm{yr}^{-1}$ today to $140-170 \mathrm{EJ} \mathrm{yr}^{-1}$ by 2100 , coming mostly from agricultural production. To maintain ecological functions approximately $40 \%$ is required to remain in the field, and a further $20-30 \%$ is diverted towards alternative uses. Of the remaining potential (approximately $50 \mathrm{EJ} \mathrm{yr}^{-1}$ in 2100), more than $90 \%$ is available at costs $<10 \$_{2005} \mathrm{GJ}^{-1}$. Crop yield improvements increase residue productivity, albeit at a lower rate. The consequent decrease in agricultural land results in a lower requirement of residues for erosion control. The theoretical potential is most sensitive to baseline projections of agriculture and forestry demand; however, this does not necessarily affect the available potential which is relatively constant across scenarios. The most important limiting factors are the alternative uses. Asia and North America account for two-thirds of the available potential due to the production of crops with high residue yields and socioeconomic conditions which limit alternative uses.
\end{abstract}

Keywords: biomass, global potential, integrated assessment, residues, scenario analysis, supply curve

Received 16 January 2015; revised version received 25 April 2015 and accepted 23 May 2015

\section{Introduction}

Residues from agricultural and forestry operations are regarded as a possible primary source of biomass for energy and material uses. Their use is attractive as they are not related to direct or indirect land-use change issues, and they are estimated to have a low cost as they are by-products of existing operations. Many integrated assessment models (IAMs) show that residues may play an important role as a primary energy source, especially in scenarios with strict climate mitigation (Rose et al., 2014). However, the availability and associated costs of residues are poorly represented in IAMs: often using a generic supply curve with little biophysical and socioeconomic backing (Berndes et al., 2003; van Vuuren

Correspondence: Vassilis Daioglou, tel. +31 30253 5392,

fax +31 30253 7601, e-mail: v.daioglou@uu.nl et al., 2010). Furthermore, there is little understanding on how the availability of this resource is related to the intensity of agriculture and forestry operations and how it may be limited by current alternative uses such as feed for livestock and fuel use in poor households (Chum et al., 2011).

A number of studies have estimated the potential of residues in 2050, with a range of 15-280 EJ $\mathrm{yr}^{-1}$ globally (Berndes et al., 2003; Hoogwijk et al., 2005; Hamelinck \& Hoogwijk, 2007; Dornburg et al., 2010; Chum et al., 2011). This large range is itself an indication of the poor understanding of the drivers for availability, the inconsistent methodologies that are used and the lack of a comprehensive evaluation of residue generation and alternative uses (Searle \& Malins, 2014). Estimates of bioenergy production from residues need to account for ecological constraints and alternative uses of the total potential (IEA, 2010). Studies agree that agriculture and 
forestry production form the most important source of residues, and consequently, most studies in the literature estimate the potential by multiplying total crop or forest production by 'residue production' and 'recoverability' factors. These studies lack a physical representation of residue productivity, ecological functions, and alternative uses, as well the impacts of changes in the intensity of agricultural and forestry systems (Berndes et al., 2003). Integrating detailed information on agriculture and forestry residue productivity with biophysical and economic models would allow for a better understanding of the availability of this resource under different scenarios (Wicke et al., 2014).

This study seeks to address these issues by assessing the availability of residues for advanced energy and material uses by investigating the mass flows while accounting for ecological and alternative uses. We develop and apply a methodology which projects residue availability within the integrated assessment model IMAGE (Stehfest et al., 2014). We project the global potential of residues to 2100 by accounting for changes in the demand of agricultural and forestry products as well as their intensity of production. Subsequently, we determine the volume of residues required for ecological functions and the demand of residues for alternative uses. Finally, we project supply curves for the available potential accounting for location-specific collection and transport costs. As a single integrated assessment model is used, the projections are internally consistent and the effect of changes in the agricultural, forestry, livestock and energy systems can be assessed.

In this study, we describe the methodology used to determine the available potential of residues and the supply curves. Furthermore, we outline the different scenarios used to assess projections of residue availability. Following, we present the results of the reference and sensitivity scenarios, highlighting the main drivers and constraints. Finally, we offer a discussion on the methodology, a comparison of our results with existing literature, and the conclusions of this study.

\section{Materials and methods}

In the context of bioenergy, residues are typically defined as by-products associated with food/fodder and forest sector production and processing (Chum et al., 2011). Consequently, residue generation is driven by the demand and production methods of the agriculture and forestry sectors. Part of these residues are already used for other purposes, such as maintenance of ecological functions, livestock feed, and fuels for poor households (IEA, 2010). An analysis of the bioenergy potential from residues therefore would need to estimate future availability on the basis of these drivers and constraints. Here, we do so using spatially explicit projections of the production and intensity of the agriculture and forestry sectors, while accounting for ecological constraints and the use of residues for feed and traditional fuels. Maps of agriculture and forestry production as well as residue demand for other uses are derived from the IMAGE model (see Supporting Information), providing a consistent description of different forms of land use, land-use intensity and demand for feed and fuel.

Three levels of residue potentials are evaluated as follows: the theoretical, ecological and available potential. These potentials and the different residue sources are defined in Table 1 . The calculation process employed in this study is outlined in Figure 1. To maintain consistency for different residue uses, in the calculations all quantities are measured in tons (wet basis). As the focus of this study was to project the residue availability for bioenergy, all results in this study are presented in energy terms using relevant moisture contents and higher heating values (HHV) (Table 2).

\section{Theoretical potential}

The theoretical potential comprises of the absolute maximum volume of residues produced given projections in agricultural and forestry productivity. It acts as an upper limit of the availability and does not take into account environmental or economic constraints, recoverability and possible current uses. Below, the calculation method for agriculture and forestry harvest and process residues is presented.

\section{Agricultural residues}

The production of agricultural residues depends on the volume of agricultural production, the crops being produced and the yield of these crops (Kim \& Dale, 2004; Chum et al., 2011). In this study, agricultural residues are defined as above ground straw or stalks. The yield affects residue potential through the residue to product ratio (RPR), defined as the ratio of above ground crop production to the total grain production (Lal, 2005). Data from a number of studies indicate the RPR varies across different crop types and tends to decrease with increasing yields (see references in Scarlat et al., 2010). This is because gains in crop yields improve the production of the harvestable component rather than the residue component.

The IMAGE model includes crop production (and yields) for the following groups: temperate cereals, rice, maize, tropical cereals, sugarcane, pulses, roots \& tubers, and oil crops. The relationship between crop yield and RPR used in this study is shown in Table 2. For pulses, roots \& tubers, and oil crops, no meaningful relationship could be determined from the literature, and thus, the arithmetic mean of the available data was used. The IMAGE model also includes a land-use category of 'other crops' covering all other crops not mentioned above. We have divided the land use of 'other crops' amongst, vegetables, fruit, and fibre crops based on FAO data (2014), with the shares of each of these crops kept constant in future projections. As yields of each of these crops are not provided from IMAGE, a residue to surface area ratio (RSR), determined from literature, was used (Di Blasi et al., 1999; Gemtos \& Tsiricoglou, 1999; Lal, 2005; GarciaGalindo \& Royo, 2009). This crop-specific factor determines the tons of residue production per $\mathrm{km}^{2}$ of crop production. 


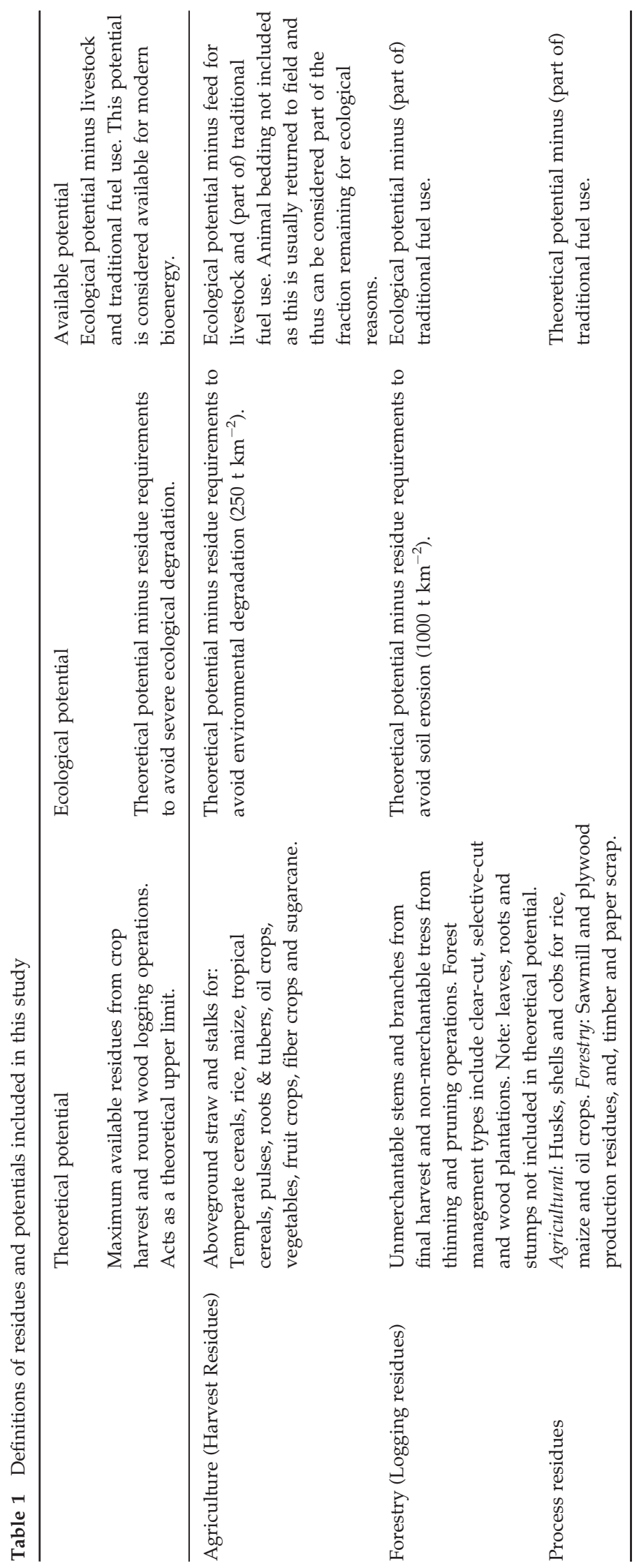




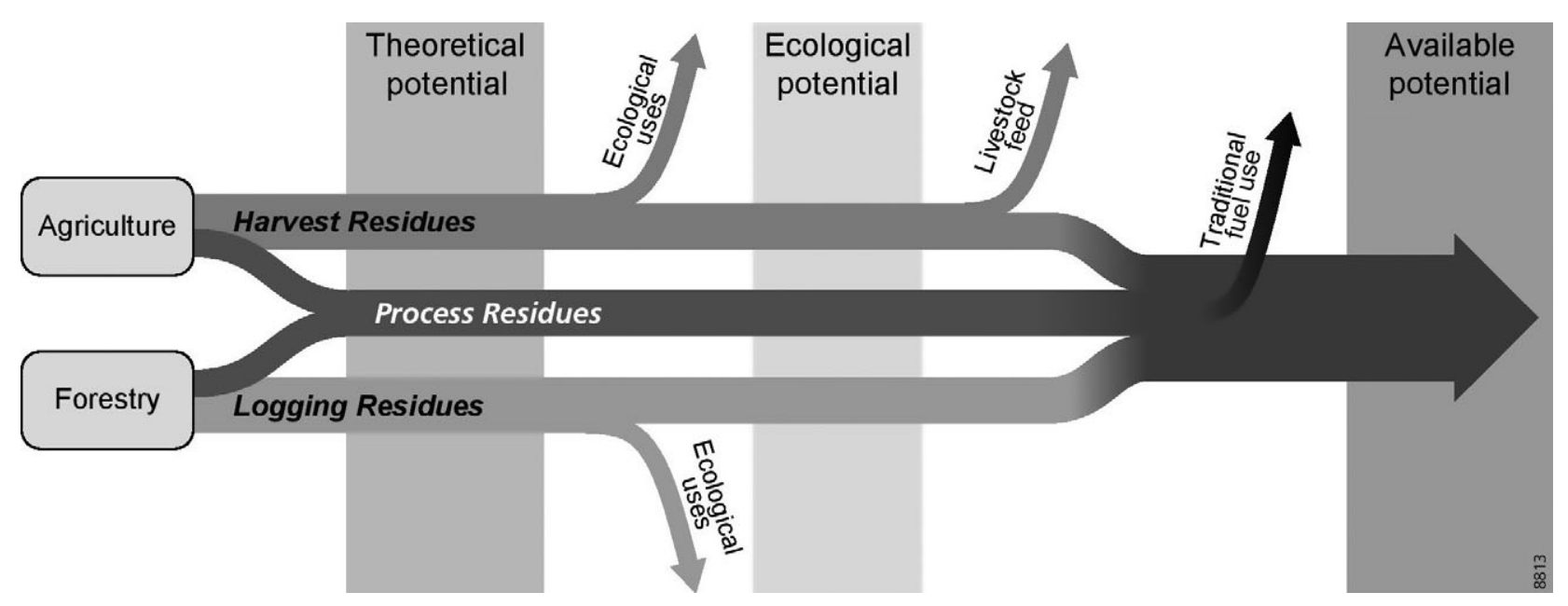

Fig. 1 Flowchart indicating methodology used to determine the residue availability. Outflows leading to different potentials were shown, and data inputs were indicated in ovals.

Note:

Figure for illustration purposes only, flow sizes may be of different magnitudes.

Table 2 Agricultural crops included in assessment, proposed correlations between RPR and yield and assumed higher heating value

\begin{tabular}{|c|c|c|c|}
\hline Crop & $\operatorname{RPR}\left(t_{\text {residue, wet }} t_{\text {product }}^{-1}\right)^{*}$ & Moisture content (\%) & HHV (GJ t wet $^{-1}$ ) \\
\hline Temperate Cereals $\dagger$ & $-0.281 \times \operatorname{Ln}($ Yield $)+2.7423$ & 12 & 16 \\
\hline Rice & $-0.925 \times \operatorname{Ln}($ Yield $)+7.371$ & 13 & 13 \\
\hline Maize & $-0.138 \times \operatorname{Ln}($ Yield $)+1.8681$ & 12 & 16 \\
\hline Tropical Cereals & $-0.266 \times \operatorname{Ln}($ Yield $)+3.108$ & 11 & 15 \\
\hline Sugarcane & $-0.18 \times \operatorname{Ln}($ Yield $)+1.4289$ & 10 & 16 \\
\hline Pulses & 1.24 & 15 & 15 \\
\hline Roots \& Tubers & 0.46 & 73 & 4 \\
\hline Oil Crops & 1.53 & 8 & 16 \\
\hline Other crops & $\operatorname{RSR}\left(t_{\text {residue,wet }} \mathrm{km}^{-2}\right)$ & Moisture content (\%) & $\operatorname{HHV}\left(G J \mathrm{t}_{\mathrm{wet}}{ }^{-1}\right)$ \\
\hline Vegetables & 2734 & 80 & 3 \\
\hline Fruit & 342 & 40 & 11 \\
\hline Fibre & 559 & 17 & 15 \\
\hline
\end{tabular}

Di Blasi et al. (1999), Gemtos \& Tsiricoglou (1999), , Kim \& Dale (2004), Lal (2005), Garcia-Galindo \& Royo (2009), Scarlat et al. (2010), CGPL (2010), ECN (2012), Jiang et al. (2012), Xu et al. (2013).

${ }^{*}$ Crop yields are measured in wet tons per $\mathrm{km}^{2}$.

$\dagger$ Scarlat et al. (2010) assessed wheat, rye, oats and barley separately. In this study, the aggregate of these crop categories are used for 'Temperate Cereals' by taking the average RPR of these crops at different yield levels.

The theoretical potential is calculated per crop type and grid cell using IMAGE maps of crop area and yields and the equations shown in Table 2. The theoretical potential of agricultural residues (AgrTheo), in tons, is calculated using Eqn (1).

$$
\text { AgrTheo }_{c, i}=\mathrm{RPR}_{c, i} \times \text { CropArea }_{c, i} \times \text { CropYield }_{c, i}
$$

where CropArea and CropYield are the cultivation area $\left(\mathrm{km}^{2}\right)$ and yield $\left(\mathrm{t} \mathrm{km}^{-2}\right)$, respectively, as projected by the IMAGE model. The subscripts $c$ and $i$ stand for crop and grid cell, respectively.

For process residues, it is assumed that they accrue during the processing of the main product. Thus, their potential is deter- mined by multiplying the production of each crop by a residue generation factor. These are set as 0.2 for rice husks, 0.3 for maize cobs and husks, and 0.1 for oil crops (Koopmans \& Koppejan, 1997; Yamamoto et al., 2001; Smeets et al., 2007a; CGPL, 2010).

\section{Forestry residues}

The theoretical potential of forestry residues is very site specific and depends on a number of aspects such as biome, tree species and their diversity, management type (clear-cut, selective cut, reduced impact logging and plantation), silvicultural practices (thinning, pruning) and end product (timber, pulp \& 
paper). Also, the residue sources themselves are diverse (twigs, branches, stumps, roots or low-quality stems; Buck, 2013; van Dijk, 2014). This means that forestry residue potential cannot be aggregated easily. Most literature sources simply assume a percentage of the total tree volume is residue. This is usually set to 30-60\% (Koopmans \& Koppejan, 1997; Smeets \& Faaij, 2007b; USDE, 2011). A study by Lauri et al. (2014) estimates that, in tropical zones, $20-50 \%$ of growing stock are of species relevant for roundwood production and harvest residues make up $20 \%$ of merchantable trees.

In IMAGE, harvesting can be conducted under three possible management types: clear-cut, selective cut and wood plantations, as defined in Arets et al. (2010). While a specific forest does not produce merchantable wood annually (due to growth cycles), in IMAGE, the production is averaged over the growth cycle and is thus considered annual. In this study, projections of this annual wood production are used together with harvest residue generation factors, per biome and management type, derived from literature to determine the theoretical potential. These residue generation factors are shown in Table 3 and include all forestry operations (thinning, intermediate cut and final cut) and represent the ratio of residues to merchantable wood production over the entire growing cycle.

These ratios have been determined by investigating average species diversity, crown/stem ratios, wood removal rates, rotation lengths and silvicultural practices (Buck, 2013; van Dijk, 2014). A representative tree species is selected for each biome, with a unique crown/stem ratio. Wood removal rates, rotation lengths, stocking density and other practices vary per management type. Thus, we determine, over the entire growing cycle, residue production from thinning, intermediate and final harvest. Consequently, the ratio of residue to merchantable wood over the entire growing cycle is determined. Roots and stumps are not included as their removal leads to significant disruption to the forest area. Approximately half of the residues come from thinning and the other half from the final harvest, with thinning being more important in plantations.
For forests under clear-cut management, it is assumed that a whole natural forest area is completely felled and harvested. In selective cut, only trees with the highest economic value are felled. This management type is mainly practiced in tropical forests where only few commercial trees are available due to the heterogeneous nature of these forests (Arets et al., 2010). As only relevant trees are felled, this management type has the lowest residue productivity. Wood plantations contain selected tree species which may be endemic or exotic. These forests are intensely managed, may be irrigated and apply pest control and fertilizer use to maximize production. Wood plantations tend to have higher residue generation potentials due to very short rotation periods, removal of unmerchantable stands, high stocking density and intense silvicultural management such as pruning and precommercial thinning (Hakkila, 2004; van Dijk, 2014). Overall, boreal forests have higher residue generation rates than other forest types due to higher crown-to-stem ratios (Standish et al., 1985). The theoretical potential of forestry residues (ForTheo), in tons, is calculated using Eqn (2).

$$
\text { ForTheo }_{B, i}=\frac{\text { ForTheoFrac }_{B, i}}{100} \times \text { WoodProd }_{B, i}
$$

where ForTheoFrac is the ratio of forest residues to merchantable wood production, as listed in Table 3, and WoodProd is the total merchantable wood production which is provided from IMAGE. The subscripts $B$ and $i$ stand for forest biome and grid cell, respectively.

Concerning process residues from wood production (sawdust, trimmings, shavings etc.), the production of merchantable wood is multiplied by a process residue generation factor (constant across biomes and management types). This is set at 0.3 (Koopmans \& Koppejan, 1997; Yamamoto et al., 2001; Smeets \& Faaij, 2007b; CGPL, 2010; Lauri et al., 2014).

\section{Ecological potential}

Residues perform a number of ecological functions such as protection from soil erosion, maintaining soil organic carbon

Table 3 Residue fraction per unit merchantable wood removed (\%) for each forest and management type

\begin{tabular}{|c|c|c|c|}
\hline \multirow[b]{3}{*}{ Forest biome (IMAGE) } & \multicolumn{3}{|c|}{ Management type } \\
\hline & Clear cut & Selective cut & Wood plantation \\
\hline & \multicolumn{3}{|c|}{ Residue production per wood production (\%) } \\
\hline Boreal & 69 & & 78 \\
\hline Wooded tundra & & NA* & \\
\hline $\begin{array}{l}\text { Cool conifer } \\
\text { Temperate mixed } \\
\text { Temperate deciduous }\end{array}$ & 53 & & 63 \\
\hline $\begin{array}{l}\text { Savanna } \\
\text { Warm mixed } \\
\text { Tropical woodland } \\
\text { Tropical forest }\end{array}$ & 39 & 18 & 52 \\
\hline
\end{tabular}

Nilsson et al. (2002), Buck (2013).

* Selective cut is not practiced in these biomes. 
(SOC), improving water infiltration, reducing soil moisture evaporation rates and preservation of biodiversity (Richardson et al., 2002; Andrews, 2006; Blanco-Canqui \& Lal, 2007; Lattimore et al., 2009; Lamers et al., 2013). The volume of residues required to provide these ecological functions depends on a number of factors including soil types, climate conditions, crop rotation and tillage. Assessing the ecological potential at this level of detail is not possible, and thus, we apply a global constraint which would ensure an adequate level of environmental protection. Concerning SOC, studies agree that it is much more sensitive to the tillage employed, and with appropriate tillage techniques, residue removal rates can increase significantly without affecting SOC content (Reicosky et al., 2002; Johnson et al., 2006). In this study, it is assumed that ecological services are maintained if soil erosion can be controlled by limiting the amount of residue extraction (Papendick \& Moldenhauer, 1995; Gallagher et al., 2003; Lemke et al., 2010; Glithero et al., 2013; Liska et al., 2014). We only extract surface residues as belowground residues are assumed unavailable throughout this study. Below, we show the calculation for the limitations to residue extraction for both agricultural and forestry residues.

\section{Agriculture}

Gallagher et al. (2003) determine the volume of residues required to avoid wind and water erosion for a number of different land classes. Their results show that in the most pessimistic cases, erosion constraints are met if up to 250 tons of residues remain per $\mathrm{km}^{2}$ of cultivated land. This is also the constraint used in this study. The formulation used to determine the agricultural ecological potential, in tons, is shown in Eqn (3).

$$
\operatorname{AgrEco}_{c, i}=\max \left[\text { AgrTheo }_{c, i}-\left(250 \times \text { CropArea }_{c, i}\right), 0\right]
$$

\section{Forestry}

Literature states that additional to leaves and small branches, a minimum of $1000 \mathrm{t} \mathrm{km}^{-2}$ of forestry residues from final harvest should remain on site to maintain soil properties (Graham et al., 1994). As stated above, in this study, we include residues from various stages of forest growth as well as the final harvest and these are spread over the entire growing cycle. Following the method used to determine the theoretical potential, we reduce the residues, only from the final harvest, by $1000 \mathrm{t} \mathrm{km}^{-2}$ and determine the ratio of the ecological to the theoretical potential (ForEcoFrac ${ }_{B, i}$ ). This ranges between 60 and $90 \%$ depending on the biome. Note that (nonfoliage), residues produced during intermediate operations $(\approx 50 \%$ of theoretical potential) are assumed useable, and thus, ForEcoFrac ${ }_{B, i}$ depends on residue production during final harvest only. The ecological potential is calculated according to Eqn (4).

$$
\text { ForEco }_{B, i}=\text { ForTheo }_{B, i} \times \text { ForEcoFrac }_{B, i}
$$

\section{Available potential}

Residue availability can be limited by other uses which are dependent on local physical and economic circumstances. The most important current uses of agricultural and forestry residues are as a source of feed for livestock and fuel in poor households (Koopmans \& Koppejan, 1997; IEA, 2010; USDE, 2011). IMAGE provides projections of demand of residues for both livestock feed (based on projected developments in livestock demand and production) and traditional fuel use in households (based on changes in affluence). These projections are carried out on a regional level according to the 26 IMAGE regions (Stehfest et al., 2014). For the available potential (AvailablePot), it is assumed that residue demand for livestock feed is met solely from agricultural residues. Concerning traditional fuels, It is assumed that $50 \%$ of traditional fuels are residues, the rest coming from coal, household waste, charcoal, fuel wood, dung and others (WHO, 2011). Residue-based traditional fuels are supplied from an aggregate of harvest, logging and process residues (AgrProc and ForProc for agricultural and forestry process residues, respectively). Available potential is determined on a regional basis, $R$.

$$
\begin{aligned}
\text { AvailablePot }_{R}=[ & \left(\text { AgrEco }_{R}-\text { FeedDem }_{R}\right)+\text { ForEco }_{R}+\text { AgrProc }_{\mathrm{R}} \\
& \left.+ \text { For Proc }_{\mathrm{R}}\right]- \text { TradFuelDem }_{R}
\end{aligned}
$$

\section{Costs}

Supply curves of the available potential are generated based on the main cost components determined from literature. Data sources are often region or even site specific, and thus, in this global study, the data have to be made more generic. Costs are scaled across regions based on the relative labour costs as projected by the scenarios. All monetary values are expressed in US\$2005.

\section{Agricultural residues}

Detailed cost estimates for agricultural residues across different world regions and crops are scarce. In this study, estimates are based on studies and surveys focussing on US agricultural residue collection due to their comprehensive nature and the ability to compare costs amongst them (Gallagher et al., 2003; Edwards \& Johanns, 2014; Thompson \& Tyner, 2014).

Harvest costs. These costs are assumed to be constant on a per-area basis, such as chop and bale, which are related to trips across the field. Consequently, areas or crops that produce more residues will have lower harvest costs (on a per GJ basis). After Gallagher et al. (2003), these are set at $4800 \$ \mathrm{~km}^{-2}$.

Operations. These include on-farm hauling $\left(0.1 \$ \mathrm{GJ}^{-1}\right)$ which is the same for all crops, as well as costs of replacing nutrients (via the application of fertilizer) due to the removal of residues. Fertilizer costs vary across crops $\left(0.3-0.5 \$ \mathrm{GJ}^{-1}\right)$. All the values are taken from Gallagher et al. (2003).

Storage and drying. These costs were estimated at $1.2 \$ \mathrm{GJ}^{-1}$ and assumed constant across all crops (Thompson \& Tyner, 2014).

Transport. The cost of transporting bales to a processing facility are set at $0.012 \$ \mathrm{GJ} \mathrm{km}^{-1}$ (Edwards \& Johanns, 2014). Transport distance is inversely related to population density and assumed to increase exponentially as population density 
approaches 0 . With this function, globally transport costs range from 0.2 to $5 \$ \mathrm{GJ}^{-1}$.

For process residues, a single price is given for all types of crops and processes. These residues are generated in grain-processing facilities, and thus, their cost could be considered zero or even negative. However, we attach a price to them to cover collection and handling costs, and as once a demand is created, negative costs will not persist (Junginger et al., 2001; USDE, 2011). The price of agriculture process residues is set at $2 \$ \mathrm{GJ}^{-1}$ (Gregg \& Smith, 2010; USDE 2011).

\section{Forestry residues}

Details on forest residue collection methods and cost estimates are sparse and tend to focus on European boreal forests. Two comprehensive studies have been used to get cost estimates. Junginger et al. (2005) has identified cost reduction trends in forest residue collection in Sweden by assessing different components of the cost structure. Eriksson \& Gustavsson (2010) assess six different residue collection systems, for Sweden and Finland, by comparing the cost components. Based on these studies, the following cost structures have been estimated.

Forwarding. Costs of forwarding of residues or bundles from the forest area to a roadside range from 0.3 to $0.9 \$ \mathrm{GJ}^{-1}$. This study assumes forwarding costs at $0.6 \$ \mathrm{GJ}^{-1}$.

Chipping/Compressing. The literature gives costs of roadside chipping or in forest bundling and compressing ranging from 1 to $1.9 \$ \mathrm{GJ}^{-1}$. The higher values are from the 1980s as the chipping process has shown significant cost reduction. This study assumes chipping/compressing costs to be $1.2 \$ \mathrm{GJ}^{-1}$.
Transport. Same method is used as with agricultural residues.

Additional costs. These include stumpage fees, overhead costs, covering of piles, operation and maintenance. Junginger et al. (2005) estimated them as 15\% of total cost, while Eriksson \& Gustavsson (2010) gave absolute costs for each collection method. In all cases, these costs varied between 0.1 and 1.4 $\$ \mathrm{GJ}^{-1}$. This study assumes additional costs to be $0.5 \$ \mathrm{GJ}^{-1}$.

\section{Scenarios}

To investigate the dynamics of residue availability, we project the potentials and costs for three scenarios: Medium, Optimistic and Pessimistic. The scenarios are based on the Shared Socioeconomic Pathways (SSPs) - as set of scenarios recently developed to support climate and global environmental research. The SSPs describe plausible alternative trends in the evolution of society and ecosystems over a century timescale (van Vuuren et al., 2014). The purpose of the SSP scenarios is to explore how diverging socioeconomic conditions (such as demographic, political, social, cultural, institutional, lifestyle, economic and technological aspects) affect the energy and the land-use system, and greenhouse gas emissions, and what challenges result for mitigation and/or adaptation to climate change ( $\mathrm{O}^{\prime} \mathrm{Neill}$ et al., 2014). Population and GDP projections are taken from the SSP database (IIASA, 2015). These pathways have been implemented in the IMAGE model framework resulting in a quantitative description of the global energy, land and environmental systems (see Supporting Information). The Medium scenario represents a business-as-usual development of socioeconomic indicators. The Optimistic scenario represents a world with relatively low mitigation and adaptation challenges to climate change, and the Pessimistic scenario represents a world where

Table 4 Qualitative description of baseline and sensitivity scenarios

\section{Reference scenarios \\ Optimistic}

Pessimistic

Sensitivity Scenarios

Medium - Extensive

Medium - Intensive
The Optimistic scenario is based on SSP1 and illustrates a world with reduced mitigation and adaptation challenges to climate change. The global population stabilizes by 2050 and slowly decreases thereafter. Per-capita income, consumption and access to modern energy increase significantly. The agricultural system is characterized by optimistic improvements in crop yields, increased use of irrigation and intensification of the livestock system

The Medium projection is based on SSP2, a continuation of current trends and assumes intermediate challenges to climate adaptation and mitigation. Population increases and stabilizes by 2090, leading to increased demand of agricultural, livestock and forestry products compared to the Optimistic case. Developments in the agricultural system also follow business-as-usual projections, as described by FAO (Alexandratos and Bruinsma, 2012)

The Pessimistic scenario is based on SSP3 and depicts a world dominated by regional competition. This includes a strong increase of population throughout the projection period, leading to increased demand in agriculture, livestock and feed products. Yet per-capita income and consumption is lower than in the other scenarios, and residues play a more important role as a traditional fuel. It represents a 'regionalized' world with low technology transfer, low improvements in yields and limited intensification in livestock systems

Population and GDP of Medium with agricultural intensity parameters of Pessimistic (i.e. less intensification compared to reference Medium)

Population and GDP of Medium with agricultural intensity parameters of Optimistic (i.e. more intensification compared to reference Medium) 
Table 5 Relative changes of key indicators for all reference scenarios $(2010=100)$. IMAGE provides projections of the volume demand and production intensity of the agricultural and forestry sectors. Aggregate residue productivity $\left(\mathrm{GJ} \mathrm{km}^{-2}\right)$ for the theoretical and available potentials determined from present methodology

\begin{tabular}{|c|c|c|c|c|c|c|}
\hline & $\begin{array}{l}\text { Reference } \\
\text { scenario }\end{array}$ & 2010 & 2030 & 2050 & 2080 & 2100 \\
\hline \multicolumn{7}{|l|}{ Inputs from IMAGE } \\
\hline \multirow{3}{*}{$\begin{array}{l}\text { Demand for agricultural } \\
\text { and forestry products }\end{array}$} & Optimistic & 100 & 129 & 150 & 156 & 160 \\
\hline & Medium & 100 & 134 & 155 & 166 & 174 \\
\hline & Pessimistic & 100 & 145 & 169 & 186 & 199 \\
\hline \multirow{3}{*}{$\begin{array}{l}\text { Intensity of production } \\
\text { (agriculture and forestry) }\end{array}$} & Optimistic & 100 & 144 & 179 & 204 & 222 \\
\hline & Medium & 100 & 143 & 169 & 192 & 219 \\
\hline & Pessimistic & 100 & 142 & 161 & 178 & 196 \\
\hline \multicolumn{7}{|l|}{ Results } \\
\hline \multirow{3}{*}{$\begin{array}{l}\text { Residue productivity for the } \\
\text { theoretical potential }\end{array}$} & Optimistic & 100 & 110 & 116 & 116 & 117 \\
\hline & Medium & 100 & 112 & 119 & 120 & 120 \\
\hline & Pessimistic & 100 & 107 & 110 & 112 & 113 \\
\hline \multirow{3}{*}{$\begin{array}{l}\text { Residue productivity for the } \\
\text { available potential }\end{array}$} & Optimistic & 100 & 115 & 127 & 128 & 130 \\
\hline & Medium & 100 & 120 & 133 & 137 & 139 \\
\hline & Pessimistic & 100 & 116 & 121 & 125 & 128 \\
\hline
\end{tabular}

these challenges are high (Table 4). The diverging developments in each scenario lead to different agricultural and forestry product demands as well as intensities of production. Furthermore, socioeconomic differences between the scenarios lead to varying livestock feed and household energy use, which affect the alternative use of residues. One of the major uncertainties in scenarios on global agriculture and land use is the intensity of agricultural production. It is well known that, in many regions, large potentials exist for increasing the efficiency of livestock systems (e.g. via improved feed composition, better grassland management and improved breeds) and increasing crop yields (e.g. via increasing fertilizer input, managing pests and diseases and improving plant breeds). Changes in these intensity parameters will have strong implication for land use. To investigate the effect of agricultural intensity (i.e. isolate for changes in population and income), we also run sensitivity scenarios on the Medium scenario. A qualitative description of the reference and sensitivity scenarios is shown in Table 4.

\section{Results}

It is important to highlight how the main driving forces of the results evolve over the projection period for each scenario. These are shown, indexed to 2010, in Table 5. The demand of agricultural and forestry products (which are primarily driven by population growth) is lowest for the Optimistic and highest for Pessimistic cases. Conversely, the intensity of production (i.e. crop yields) is highest for the Optimistic and lowest for Pessimistic case. Consequently, the Optimistic case has the lowest total land use and Pessimistic, the highest. The residue productivity (measured in GJ km ${ }^{-2}$ ) depends on which crops are produced, crop yields, cropping intensities and the forest management types. Overall, an increase in the productivity for the theoretical potential over time is witnessed, driven by increases in crop yields. The lower rate of increase for residue productivity with respect to crop yields is due to decreases in residue to product ratios. The productivity for the available potential, which drive the final costs, is determined after ecological and alternative uses are accounted for. They increase at a greater rate than the theoretical potential productivity for two reasons: (i) as residue yields increase, all gains are included in the ecological potential once the constraints are met; and (ii) alternative uses decrease for all scenarios over time. The medium scenario has the highest productivities due to a combination of high yields and demand for agricultural and forestry products.

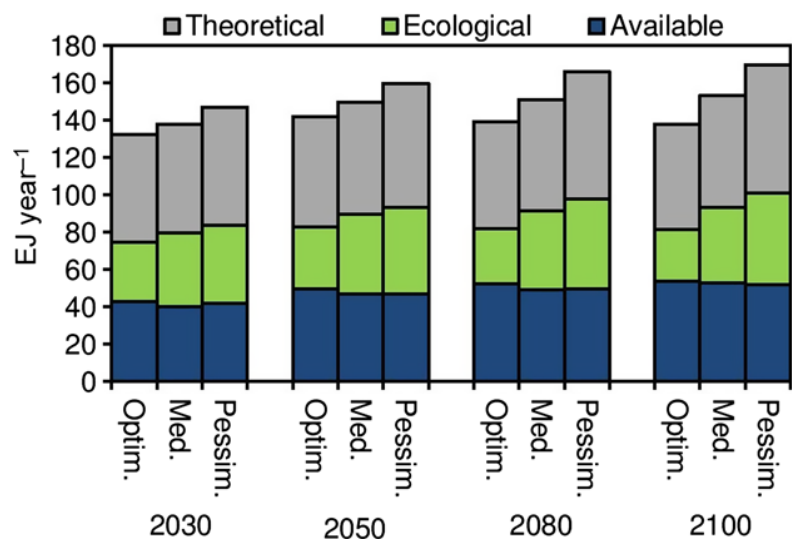

Fig. 2 Projections of theoretical, ecological and available potential. Agricultural, forestry and process residues for all reference scenarios. 


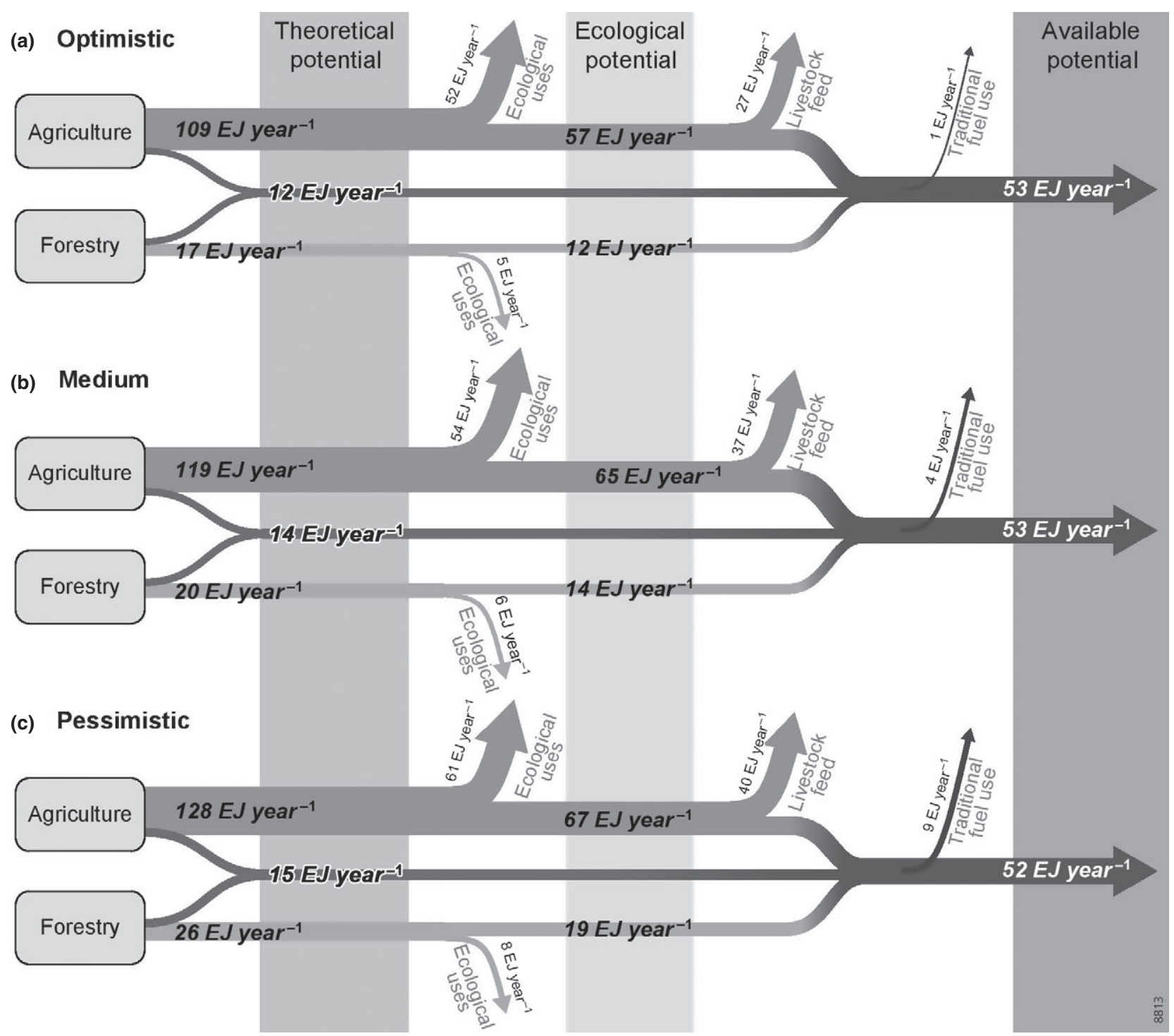

Fig. 3 Flows and potentials of residues for the (a) Optimistic, (b) Medium and (c) Pessimistic reference scenarios in 2100. Definitions of flows same as in Figure 1.

\section{Reference scenarios}

Figure 2 shows the projections of the different potentials for the reference scenarios. The theoretical potential increases over the projection period due to increases in the demand of agricultural and forestry products, with the Pessimistic case having the largest increase. The results imply that approximately 50\% of agricultural residues and $30 \%$ of forestry residues have to remain on the field for ecological services. Next, the available potential is about $50-66 \%$ of the ecological potential (thus $30-40 \%$ of the theoretical). Figure 3 shows the different flows of residues from theoretical to available potential, for all the reference scenarios.
The ecological uses depend on the land area being used and thus increase across the scenarios. This leads to a closing of the gap between scenarios for the ecological potential compared to the theoretical. Interestingly, the available potential follows a different trend than the theoretical/ecological potentials across the scenarios. Alternative uses differ significantly due to changes in livestock feed demand and the use of traditional fuels in poor households. Due to its lower economic development and extensive production modes, the Pessimistic case has the largest competing uses. In other words, even though the Pessimistic case has the highest theoretical and ecological potential in 2100, the alternative uses lead to an available potential lower than the Optimistic 
(a) Theoretical potential (GJ km-2 )

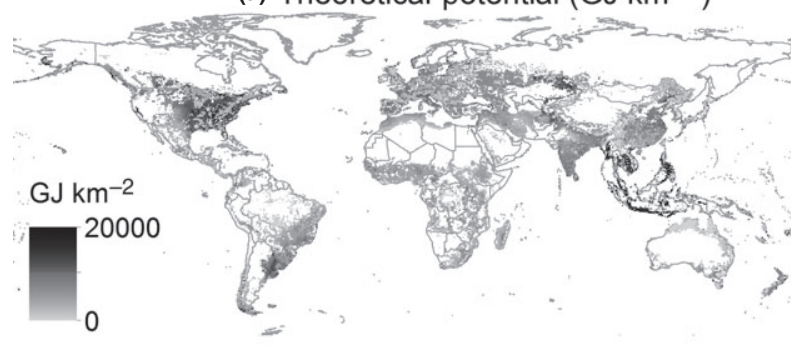

(b) Ecological potential (GJ km-2)

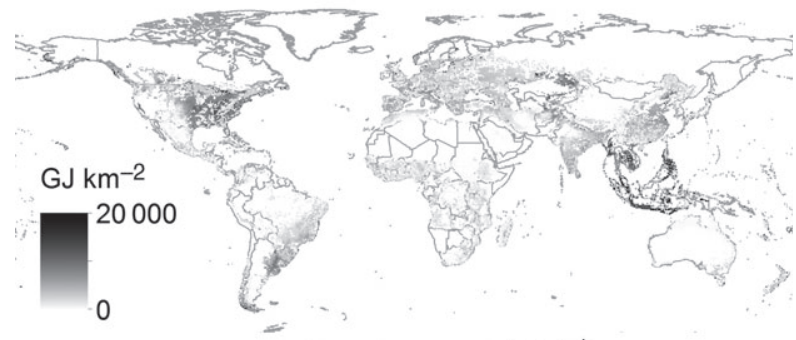

(c) Supply costs $\left(\$ \mathrm{GJ}^{-1}\right)$

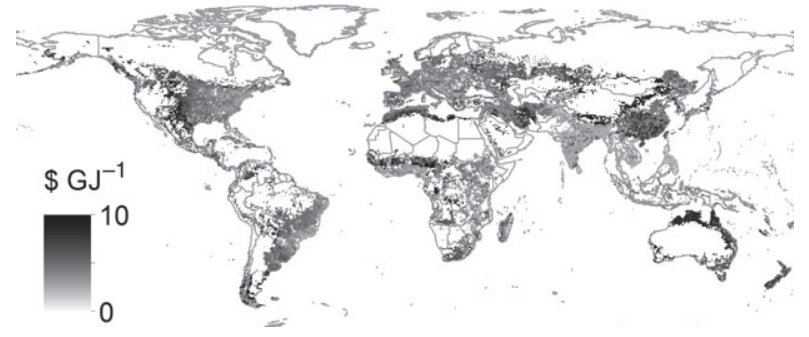

Fig. 4 Maps of (a) theoretical potential, (b) ecological potential and (c) supply costs in 2100 for the Medium scenario.

and Medium cases. It is worth noting that traditional biomass in 2008 was estimated to be approximately $40 \mathrm{EJ} \mathrm{yr}^{-1}$ globally; thus, all the scenarios assume significant progress towards energy access (Chum et al., 2011).

By 2100, Asia accounts for most of the available potential, increasing from approximately $30 \%$ today to over $40 \%$ in 2100 . This dominance is largely due to intensive production of rice in the south and oil crops (soybean and palm oil) in the south-east. Asia has large agricultural areas, and the residue productivity is the highest of the world by 2050. North America accounts for $35 \%$ of the available potential today, driven by maize production, but this decreases to $26 \%$ by 2100 . By 2100, Eastern Europe and Russia account for about $10 \%$ (from temperate cereals and forestry), while Europe, Africa, the Middle East, Oceania and Latin America account for $<10 \%$ each. Residue production in these regions is relatively low due to the production of crops with low RPR/RSR (Europe and Oceania), very low crop yields (Africa and Middle East) or high diversion of residues due to livestock feed and traditional fuel uses (Latin America, Africa and Middle East). Detailed numerical results for all scenarios and regions are available in the Supporting Information.

Figure 4 shows global maps of the (a) theoretical and (b) ecological potentials, as well as the supply costs (c). Figure 5 shows the supply curve of available residues (costs per grid cell sorted in ascending order). In both 2050 and 2100 and for all reference scenarios, over $90 \%$ of the potential is available at costs lower than $10 \$ \mathrm{GJ}^{-1}$. Over $60 \%$ is available at $5 \$ \mathrm{GJ}^{-1}$. About $25 \mathrm{EJ} \mathrm{yr}^{-1}$ are available at $<3 \$ \mathrm{GJ}^{-1}$. The cheapest available residues are supplied from Asia which enjoys high residue productivity (thus low harvest costs) and low transport costs. The large potential at 2 $\$ \mathrm{GJ}^{-1}$ are the available process residues. Regional supply curves are available in the Supporting Information.

On aggregate, the most important cost components for agricultural residues are transport costs (approximately $40 \%$ of total cost) followed by harvest costs (20-30\%). For forestry, transport costs are the most important, accounting for $50-60 \%$ of the total cost, followed by chipping and forwarding costs. Overall, Figure 5 shows that the projected supply curves do not vary much across the scenarios, largely as the available potential is very similar. Supply costs increase with increasing transport distance and decreasing residue productivity. Overall, the optimistic (and to a lesser extent the medium) scenario has the flattest supply curve due to its high residue productivity and smaller transport distances. Costs decrease between 2050 and 2100 due to improvement in residue productivity for the available potential in all scenarios.

\section{Sensitivity scenarios}

In the results so far, the variation across scenarios imply that several changes are made at the same time. The sensitivity scenarios assume the volume demand of agricultural and forestry products of the Medium scenario while adopting production intensities and competing uses of the Optimistic (intensive) and Pessimistic (extensive) cases. Figure 6 shows how the potentials change under these conditions. For the intensive case, as crop yields increase, RPR decreases, and thus, the overall increase in theoretical potential is minor. The converse is true for the extensive case where even though RPR may be higher (as overall yields are lower), the theoretical potential is slightly lower. Ecological use is proportional to land use. Thus, the intensive case, which has an overall lower land use, has a slightly higher ecological potential. By far the most important difference between the scenarios, as with the baselines, is the competing uses. The extensive scenario which also has inefficient livestock and house- 

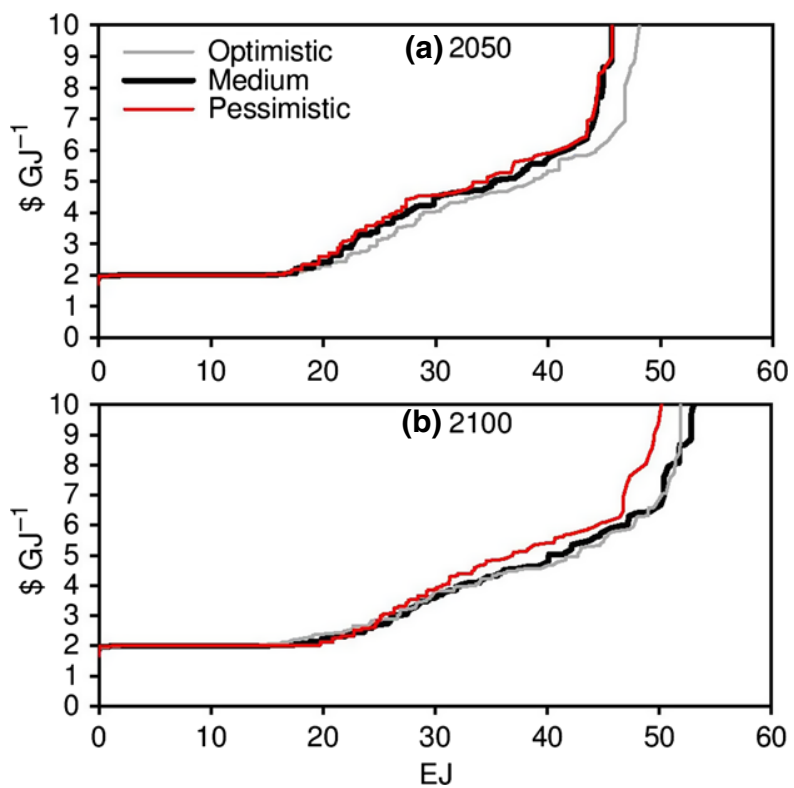

Fig. 5 Global supply curves for available residues in (a) 2050 and (b) 2100 for all reference scenarios. Only displaying available potential at $<10 \$ \mathrm{GJ}^{-1}$.

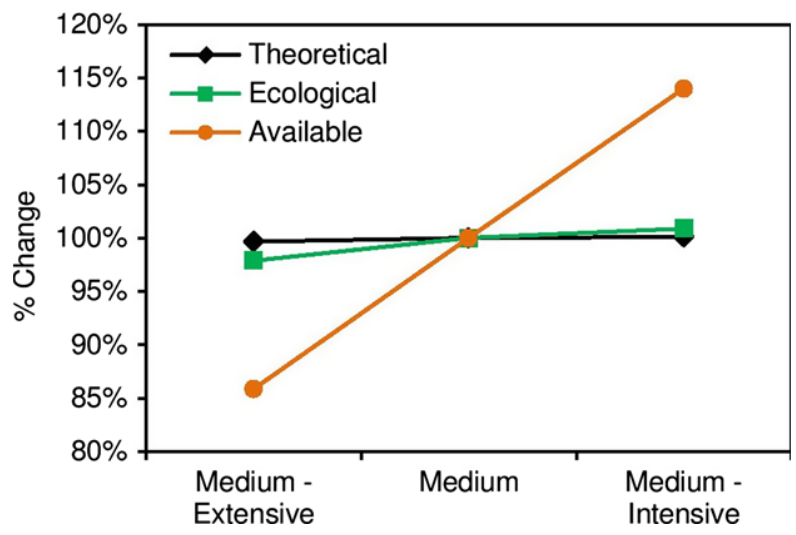

Fig. 6 Changes in the theoretical, ecological and available potentials for the sensitivity scenarios in 2100 .

hold energy-use parameters has a significantly reduced available potential due to the diversion of residues for alternative uses.

Differences in the agriculture and forestry intensity parameters and competing uses significantly affect the supply curves, as shown in Figure 7. Increasing differences in the competing uses lead to the widening divergence of supply curves throughout the projection period. For the extensive case, the costs increase rapidly due to increases in transport and harvest costs as the marginal supply is increasingly spread out over larger areas.
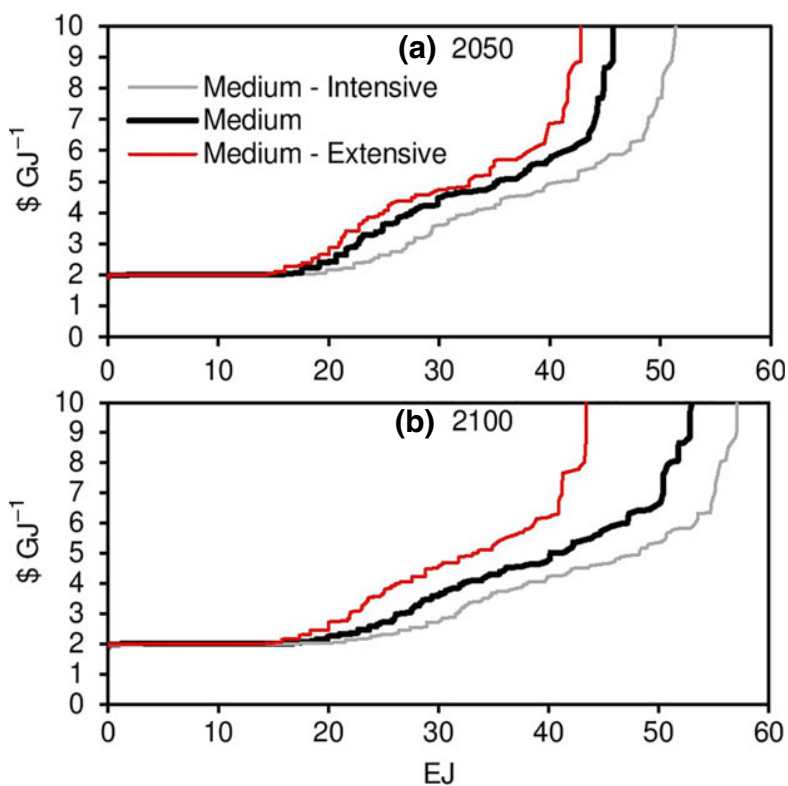

Fig. 7 Global supply curves for available residues in (a) 2050 and (b) 2100 for the Medium and sensitivity scenarios. Only displaying available potential at $<10 \$ \mathrm{GJ}^{-1}$.

\section{Discussion}

Residue generation rates and supply costs for different crops and forest types vary widely. As this study focusses on long-term global potential, assumptions consistent with the IMAGE model approach have been made. While we link agricultural residue generation to crop yields for a number of major crop groups, in reality, this factor may vary amongst different crops in each group and local conditions (soil type, climate) during crop growth. Forest residue production in this study has been varied across forest biomes and management types due to different characteristics of tree species and management processes. Scarce data availability as well as high spatial variability means that residue productivity factors cannot be easily determined across these dimensions. Despite these limitations, this study still successfully highlights trends of residue availability and costs under different scenarios and provides insights on the key elements which limit the available potential.

Maintenance of soil organic carbon (SOC) is widely cited as an important ecological service provided by residues; however, the feedbacks and mechanisms involved are unclear (Mann et al., 2002; Lal, 2005). Loss of SOC is hard to evaluate due to high spatial variability of carbon stocks and inability to detect small changes in annual levels. A number of studies which include field trials highlight that SOC levels are dependent on erosion and management as opposed to just residue cover (Reicosky et al., 2002; Lemke et al., 2010; USDE, 2011; 
Glithero et al., 2013; Liska et al., 2014). This led to the assumption adopted in this study that erosion control is the limiting factor, and the assumptions concerning the requirement of residues to avoid dangerous erosion used in this study are conservative (Papendick \& Moldenhauer, 1995; Gallagher et al., 2003). Interestingly, the study of Johnson et al. (2006) shows that at residue retention rates greater than those used in this study $\left(250 \mathrm{t} \mathrm{km}^{-2}\right)$, SOC levels may in fact increase under a number of management conditions. An improved approach could adopt the revised universal soil loss equation (RULSE) and the wind erosion equation (WEQ), which take into account soil characteristics and factors for topography and cropping management (Skidmore, 1988; USDA, 1997). Applying these methods which account for the importance of local conditions requires considerable data, especially for a global longterm study, and thus, a generalized approach had to be adopted.

Literature points to a number of management improvements, such as no-till, cropping rotation and improved forest management, which can limit erosion, SOC loss and costs (Junginger et al., 2005; USDE, 2011; B. Batidzirai, M. Junginger, A.P.C. Faaij, Submitted). This study was limited to specific agricultural and forestry practices based on IMAGE; however, it is important to note that the above measures can contribute to increasing the ecological potential of residues. Further understanding is required on how management and residue removal affect SOC and nutrient levels as well as feedbacks on crop yields. This would allow for an improved assessment of residue availability and their environmental and climate feedbacks.

For forestry, to the best of our knowledge, there is no clear consensus on the minimum amount of organic material required to remain on site to maintain ecosystem services. Most estimates (15-50\% or approximately $1000 \mathrm{t} \mathrm{km} 2$ ) are based on expert opinions and highlight the importance of local conditions (Graham et al., 1994; Herrick et al., 2009; Evans et al., 2013; Thiffault et al., 2014). The results of this study imply a 70\% ecological potential on aggregate, which is assumed recoverable. Recent literature for Canada has shown that residue recoverability rates range from $4 \%$ to $89 \%$ with a mean of 52\% (Thiffault et al., 2014). Nordic countries enjoy higher recovery rates with trials indicating $72 \%$ of residues as recoverable (Routa et al., 2013). Recovery rates depend on logging operations as well as the size, spacing and uniformity of tree species. It is important to point out that most studies only account for harvest residues, while this study also includes residue generation throughout the growth cycle (i.e. thinning and pruning). Thus, our 'final harvest' ecological potentials (and recoverability rates) are significantly smaller than the $70 \%$ value of the total recoverable potential.

In this study, competing uses of residues for livestock feed and traditional fuel use are considered out of bounds for modern bioenergy. Furthermore, it is assumed that residues are a by-product and not a function in producers' decision making. Presumably, if farmers are offered a price for residues, there may be feedbacks on the factors affecting residue availability. Potential feedbacks include changes towards livestock practices which require fewer residues (Kretschmer et al., 2012). However, it is still unclear how producers and supply chains may be affected by increased commodification of residues. Further research is needed to investigate the effect of these feedbacks on the available potential and how sensitive farmers and households may be affected.

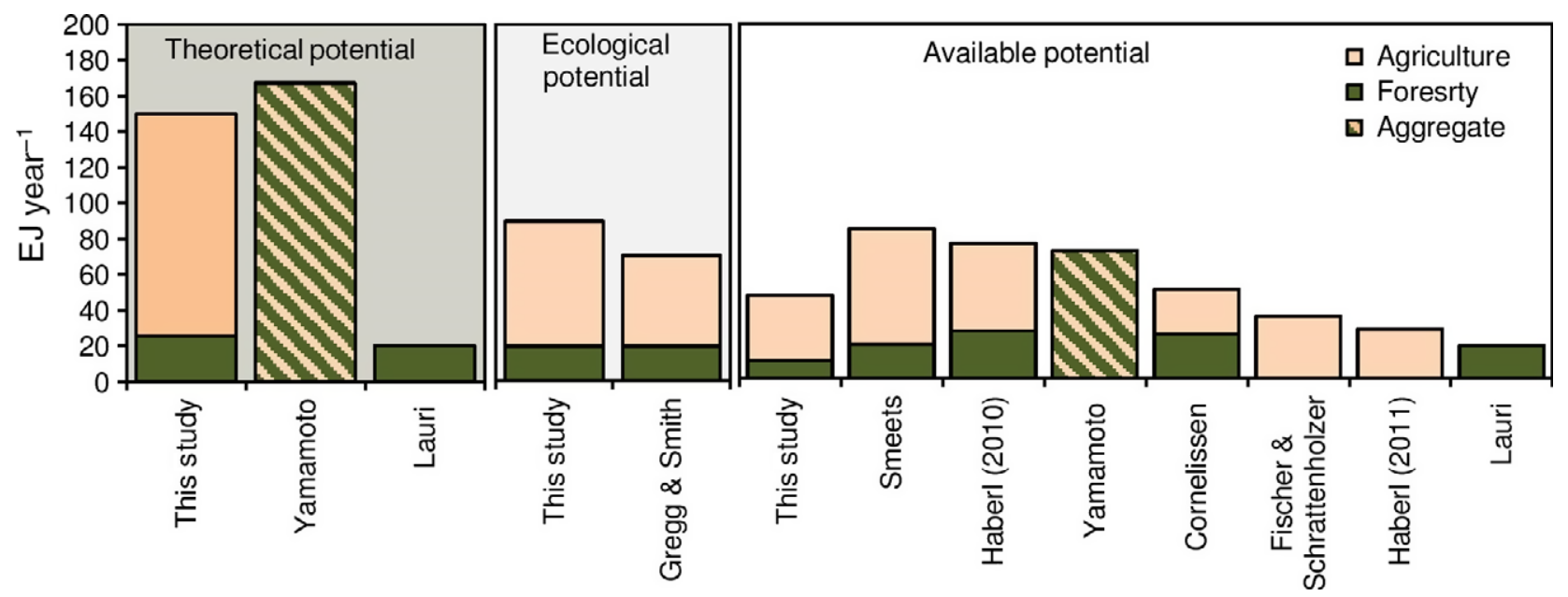

Fig. 8 Comparison of this study (Medium scenario) with the results of other global studies for 2050 where appropriate, theoretical, ecological and available potential were shown.Fischer and Schrattenholzer (2001), Yamamoto et al. (2001), Lal (2005), Smeets et al. (2007a), Gregg and Smith (2010), Haberl et al. (2010, 2011), Cornelissen et al. (2012), Lauri et al. (2014). 
Figure 8 shows how our results (medium scenario) compare with other studies that explicitly report the global potential for agricultural and/or forestry residues. Most studies follow a standard methodology: a residue fraction is assigned to the production of agricultural and forestry products. Next, they use an 'availability' or 'recoverability' fraction which accounts for - usually poorly defined - ecological, technical and economic uses. Yamamoto et al. (2001) use a global land- and energy-use model (GLUE) to determine biomass potentials. The results differ with ours because of different population projections (Yamamoto reaching 11.5 billion compared to 9 billion here) and additional residue sources (black liquor, paper scrap, animal dung, kitchen refuse and human faeces). The population projection of Yamamoto is similar to our Pessimistic scenario, which also results in a similar theoretical potential; however, our available potential is significantly lower. Lauri et al. (2014) use an economic equilibrium model focusing on the availability of woody bioenergy from harvest losses (50\% availability). Fischer \& Schrattenholzer (2001) use a global landuse model to project regional crop production. Residue productivity depends on the yields of five crop categories and an arbitrary availability fraction. The studies of Smeets et al. (2007a), Haberl et al. (2010) and Cornelissen et al. (2012) attach residue generation and availability rates (harvest, process and waste streams) to forecasts for agriculture and forestry production. Differences with this study include the inclusion of potential waste streams as well as varying requirements for livestock feed. As mentioned, the above studies limit the residue potential by assigning an availability/recoverability factor of approximately 50\%, partly representing technical limits to agricultural residue collection. Due to the long-term and exploratory nature of this study, such technical limits are not considered. However, it is worth noting that the ecological potential never surpasses $60 \%$ of the theoretical potential thus such technical limits are satisfied nonetheless.

The methodology presented here is similar to the study of Gregg \& Smith (2010) who determine the use of residues from (agriculture and forestry) using the MiniCam model. They use projections of crop yields and volume production together with constant cropspecific 'residue ratio' and 'residue retention' parameters. According to their study, an increase in yields has twofold impact on residue supply: Increased residue production and increased ecological potential as more residues can be removed without an increase in erosion rates. Our study agrees with this and further highlights that decreases in RPR as crop yields increase mean that the rate of residue production increase is lower than that of crop yields. Gregg \& Smith (2010) assume that residue supply curves follow a logistic function and
$100 \%$ of residues are available at $6 \$ \mathrm{GJ}^{-1}$. In our study, where cost components are determined based on biophysical conditions, approximately $80 \%$ are available at $6 \$ \mathrm{GJ}^{-1}$.

In contrast to the above studies, this study develops and applies a methodology which projects theoretical, ecological and available residue potentials by assessing specific mass flows. The method is used to make projections for a number of scenarios in a consistent manner within a biophysical integrated assessment model. The key insights and results can be summarized as follows:

The method offers a step forward in assessing the availability of residues for modern energy purposes: Residue generation and supply costs depend on both volume and intensity of production while the unavailable portion of residues is assessed explicitly. This method accounts for these in a spatially explicit manner within an integrated assessment model and thus consistently deals with interrelated agriculture, forestry, livestock and energy systems. Thus, the availability of residues can be assessed consistently across scenarios. This is an improvement on existing global assessments which lack spatial variation, do not explicitly account for how changes in agricultural and forestry intensity as well as broader developments may affect the availability and do not account for spatially specific determinants of costs.

The current theoretical potential is estimated to be $116 \mathrm{EJ} \mathrm{yr}^{-1}$ and is projected to increase to 140 $170 \mathrm{EJ} \mathrm{yr}^{-1}$ by 2100, depending on the scenario. Available potential increases from $33 \mathrm{EJ} \mathrm{yr}^{-1}$ to over $50 \mathrm{EJ} \mathrm{yr}^{-1}$ and does not vary much between reference scenarios: The increase is driven by growth in the demand of agricultural products, with forestry playing a smaller role. The reference scenarios show that increases in crop yields lead to significantly smaller increases residue productivity. The theoretical potential is reduced to 80-100 EJ $\mathrm{yr}^{-1}$ after erosion control is accounted for. Competing uses for livestock feed and, to a lesser extent, fuel use in poor households further reduce the available potential to approximately $50 \mathrm{EJ} \mathrm{yr}^{-1}$ for all scenarios. North America and Asia account for more than $65 \%$ of the available potential primarily due to maize production in the former, rice and oil crop production in the latter and favourable conditions concerning competing uses.

Approximately $70 \%$ of the available potential is available at a cost below $5 \$ \mathrm{GJ}^{-1}$ : This increases to more than $90 \%$ at $10 \$ \mathrm{GJ}^{-1}$. Over $20 \%$ of the potential are process residues which are assumed available at a low cost (2 $\$ \mathrm{GJ}^{-1}$ ). For nonprocess residues, costs are primarily affected by collection costs (driven by residue productivity and labour costs) and transport distance. Consequently, increases in residue productivity may reduce 
supply costs. As shown in the sensitivity scenario, all else being equal, extensive production has the highest costs as due to low residue productivity and increased transport costs.

There are differences between intensive and extensive production systems; however, the availability of this resource is most sensitive to developments of livestock feed and fuel use in poor households: Intensification leads to increased residue productivity, although at a lower rate due to changes in RPRs. For extensive production, additional to having a lower theoretical potential, the residues are spread over a larger area resulting in increases in collection and transport costs and a higher diversion of the theoretical potential to avoid erosion. Given the trade-offs between production methods and ecological constraints, the effect on crop production of different management types which may allow further residue removal (i.e. no-till) and the feedbacks of residue removal should be further investigated. By far the most important determinants of residue availability are the alternative uses of this resource as feed for livestock or fuel for poor households. Further research should focus on how commodification of this resource may increase the portion of available residues and how this may affect groups who depend on residues for certain services.

\section{Acknowledgements}

This work was conducted within the research program 'Knowledge Infrastructure for Sustainable Biomass' and was funded by the Dutch Ministries of 'Economic Affairs, Agriculture and Innovation' and 'Infrastructure and Environment'. We would like the thank Jonathan Doelman, Jelle van Minnen and Liesbeth de Waal from the IMAGE team for their support and Misha Valk, Lucy Buck and Rosemarye van Dijk for their valuable M.Sc. research on which this study is based. Furthermore, we would like to thank three anonymous reviewers for the helpful comments.

\section{References}

Andrews SS (2006) Crop Residue Removal for Biomass Energy Production: Effects on Soils and Recomendations. USDA - Natural Resource Conservation Service, http:// www.nrcs.usda.gov/Internet/FSE_DOCUMENTS/nrcs142p2_053255.pdf. (accessed 20 June 2015).

Arets EJMM, van der Meer PJ, Verwer CC, Hengeveld GM, Tolkamp GW, Nabuurs GJ, van Oorschot M (2010) Global Wood Production: Assessment of Industrial Round Wood Supply from Different Management Systems in Different Global Regions (No. alterra-rapport 1808). Alterra, Wageningen.

Berndes G, Hoogwijk M, van den Broek R (2003) The contribution of biomass in the future global energy supply: a review of 17 studies. Biomass and Bioenergy, 25, 1-28.

Blanco-Canqui H, Lal R (2007) Soil and crop response to harvesting corn residues for biofuel production. Geoderma, 141, 355-362.

Buck L (2013) Sustainable Forestry Residue Parameters (MSc., Utrecht University). 74. Available at: http://dspace.library.uu.nl/handle/1874/279518 (accessed 15 January 2015).

CGPL (2010) Biomass Resource Atlas of India. Combustion Gasification \& Propulasion Laboratory, IISc, Bangalore, India.

Chum H, Faaij A, Moriera J et al. (2011) Bioenergy. In: IPCC Special Report on Renewable Energy Sources and Climate Change Mitigation (eds Edenhofer $\mathrm{O}$ et al.), pp. 209-331. Cambridge University Press, Cambridge.
Cornelissen S, Koper M, Deng YY (2012) The role of bioenergy in a fully sustainable global energy system. Biomass and Bioenergy, 41, 21-33.

Di Blasi D, Tanzi V, Lanzetta M (1999) A study on the production of agricultural residues in Italy. Biomass and Bioenergy, 12, 321-331.

van Dijk R (2014) Forestry residue availability in the Tropics (MSc, Utrecht University). 73.

Dornburg V, van Vuuren D, van de Ven G et al. (2010) Bioenergy revisited: key factors in global potentials of bioenergy. Energy and Environmental Science, 3, 258-267.

ECN (2012) Phyllis2: Database for biomass and waste ECN

Edwards W, Johanns AM (2014) Iowa Farm Custom Rate Survey [Online]. Available at: https://store.extension.iastate.edu/Product/fm1698-pdf (accessed 15 January 2015).

Eriksson L, Gustavsson L (2010) Comparative analysis of wood chips and bundles costs, carbon dioxide emissions, dry-matter losses and allergic reaction. Biomass and Bioenergy, 34, 82-90.

Evans AM, Perschel RT, Kittler BA (2013) Overview of forest biomass harvesting guidelines. Journal of Sustainable Forestry, 32, 89-107.

FAO (2014) Crop Production Data [Online]. Available at: http://faostat3.fao.org/ faostat-gateway/go/to/download/Q/QC/E (accessed 2 July 2014).

Fischer G, Schrattenholzer L (2001) Global bioenergy potentials through 2050. Biomass and Bioenergy, 20, 151-159.

Gallagher P, Dikeman M, Fritz J, Wailes E, Gauthier W, Shapouri H (2003) Supply and social cost estimates for biomass from crop residues in the United States. Environmental and Resource Economics, 24, 335-358.

Garcia-Galindo D, Royo J (2009) Current spanish biomass co-firing potential in coal power stations. 5th Dubrovnik Conference on Sustainable Development of Energy Water and Environment Systems, Dubrovnik, Croatia.

Gemtos TA, Tsiricoglou T (1999) Harvesting of cotton residue for energy production. Biomass and Bioenergy, 16, 51-59.

Glithero N, Wilson P, Ramsden SJ (2013) Straw use and availability for second generation biofuels in England. Biomass and Bioenergy, 55, 311-321.

Graham R, Harvey AE, Jurgensen MF, Jain TB, Tonn JR, Page-Dumroese DS (1994) Managing Coarse Woody Debris in Forests of the Rocky Mountains. United States Department of Agriculture - Forest Service, Washington DC, USA.

Gregg JS, Smith SJ (2010) Global and regional potential for bioenergy from agricultural and forestry residue biomass. Mitigation and Adaptation and Strategies for Global Change, 15, 241-262.

Haberl H, Beringer T, Bhattacharya SC, Erb KH, Hoogwijk M (2010) The global technical potential of bioenergy in 2050 considering sustainability constraints. Current Opinion in Environmental Science, 2, 394403.

Haberl H, Erb KHL, Krausmann F et al. (2011) Global bioenergy potentials from agricultural land in 2050: sensitivity to climate change, diets and yields. Biomass and Bioenergy, 35, 4753-4769.

Hakkila P (2004) Developing Technology for Large-Scale Production of Forest Chips. National Technology Agency, Helsinki.

Hamelinck C, Hoogwijk M (2007) Future Scenarios for First and Second Generation Biofuels. Ecofys, Utrecht.

Herrick S, Kovach J, Padley E, Wagner C, Zastrow D (2009) Wisconsin's Forestland Woody Biomass Harvesting Guidelines (No. PUB-FR-435-2009). Wisconsin DNR Division of Forestry and Wisconsin Council on Forestry, Madison.

Hoogwijk M, Faaij A, Eickhout B, de Vries B, Turkenburg W (2005) Potential of biomass energy out to 2100, for four IPCC SRES land-use scenarios. Biomass and Bioenergy, 29, 225-257.

IEA (2010) Sustainable Production of Second-Generation Biofuels. IEA/OECD, Paris.

IIASA (2015) SSP Database [Online]. Available at: https://secure.iiasa.ac.at/webapps/ene/SspDb/dsd? Action=htmlpage\&page=about (accessed 15 January 2015).

Jiang D, Zhuang D, Fu J, Huang Y, Wen K (2012) Bioenergy potential from crop residues in China: availability and distribution. Renewable and Sustainable Energy Reviews, 16, 1377-1382.

Johnson JMF, Allmaras RR, Reicosky DC (2006) Estimating source carbon from crop residues, roots and rhizodeposits using the national grain-yield database. Agronomy Journal, 98, 622-636.

Junginger M, Faaij A, Van den Broek R, Koopmans A, Hulscher W (2001) Fuel supply strategies for large-scale bio-energy projects in developing countries. electricity generation from agriculture and forest residues in Northeastern Thailand. Biomass and Bioenergy, 21, 259-275.

Junginger M, Faaij A, Björheden R, Turkenburg WC (2005) Technological learning and cost reductions in wood fuel supply chains in Sweden. Biomass and Bioenergy, 29, 399-418.

Kim S, Dale BE (2004) Global potential bioethanol production from wasted crops and crop residues. Biomass and Bioenergy, 26, 361-375. 
Koopmans A, Koppejan J (1997) Agricultural and forest residues - generation, utilization and availability. Paper presented at the Regional Consultation on Modern Applications of Biomass Energy, Kuala Lumpur, Malaysia,

Kretschmer B, Allen B, Hart K (2012) Mobilising Cereal Straw in the EU to Feed Advanced Biofuel Production. Institute for European Environmental Policy, Brussels.

Lal R (2005) World crop residues production and implications of its use as a biofuel. Environment International, 31, 575-584.

Lamers P, Thiffault E, Paré D, Junginger M (2013) Feedstock specific environmental risk levels related to biomass extraction for energy from boreal and temperate forests. Biomass and Bioenergy, 55, 212-226.

Lattimore B, Smith CT, Titus BD, Stupak I, Egnell G (2009) Environmental factors in woodfuel production: opportunities, risks, and criteria and indicators for sustainable practices. Biomass and Bioenergy, 10, 1321-1342.

Lauri P, Havlik P, Kindermann G, Forsell N, Böttcher H, Obersteiner M (2014) Woody biomass energy potential in 2050. Energy Policy, 66, 19-31.

Lemke RL, VandenBygaart AJ, Campbell CA, Lafond GP, Grant B (2010) Crop residue removal and fertilizer $\mathrm{N}$ : effects on soil carbon in a long-term crop rotation experiment on a Udic Boroll. Agriculture Ecosystems and Environment, 135, 42-51.

Liska A, Yang H, Milner $\mathrm{M}$ et al. (2014) Biofuels from crop residue can reduce soil carbon and increase $\mathrm{CO}_{2}$ emissions. Nature Climate Change, 4, 398-401.

Mann L, Tolbert V, Cushman J (2002) Potential environmental effects of corn (Zea mays L.) stover removal with emphasis on soil organic matter and erosion. Agriculture Ecosystems and Environment, 89, 149-166.

Nilsson SG, Niklasson M, Hedin J et al. (2002) Densities of large living and dead trees in old growth temperate and boreal forests. Forest Ecology and Management, 161, 189-204.

O'Neill B, Kriegler E, Riahi K et al. (2014) A new scenario framework for climate change research: the concept of shared socioeconomic pathways. Climatic Change, 122, 387-400.

Papendick RI, Moldenhauer WC (1995) Crop Residue Management To reduce Erosion and Improve Soil Quality (No. CRR-40). US Departement of Agriculture - Agricultural Research Service, Washington DC, USA.

Reicosky DC, Evans SD, Cambardella CA, Allmaras RR, Wilts AR, Huggins DR (2002) Continuous corn with moldboard tillage: residue and fertility effects on soil carbon. Journal of Soil and Water Conservation, 57, 277-284

Richardson J, Björheden R, Hakkila AT, Smith CT (2002) Bioenergy from Sustainable Forestry: Guiding Principles and Practice. Kluwer Academic Press, Dordrecht, The Netherlands.

Rose S, Kriegler E, Bibas E, Calvin K, Popp A, van Vuuren DP, Weyant J (2014) Bioenergy in energy transformation and climate management. Climatic Change, 123 477-493.

Routa J, Asikainen A, Björheden R, Laitila J, Röser D (2013) Forest energy procurement: state of the art in Finland and Sweden. WIREs Energy Environ, 2, 602-613.

Scarlat N, Martinov M, Dallemand JF (2010) Assessment of the availability of agricultural crop residues in the European Union: potential and limitations for bioenergy use. Waste Management, 3, 1889-1897.

Searle S, Malins C (2014) A reassessment of global bioenergy potential in 2050. GCB Bioenergy, 7, 328-336.

Skidmore EL (1988) Wind erosion. In: Soil Erosion Research Methods (ed. Lal R), pp. 203-233. Soil and Water Conservation Society of America, Ankeny, IA.

Smeets EMW, Faaij A (2007b) Bioenergy potentials from forestry in 2050: as assessment of the drivers that determine the potentials. Climatic Change, 81, 353-390.
Smeets EMW, Faaij A, Lewandowski IM, Turkenburg WC (2007a) A bottom-up assessment and review of global bio-energy potentials to 2050. Progress in Energy and Combustion Science, 33, 56-106.

Standish JT, Manning GH, Demaerschalk JP (1985) Development of Biomass Equations for British Columbia Tree Species (No. BC-X-264). Pacific Forest Research Centre, Victoria, BC.

Stehfest E, van Vuuren D, Kram T, Bouwman T, Alkemade R, Bakkenes M et al (2014) Integrated Assessment of Global Environmental Change with IMAGE 3.0. Model Description and Policy Applications. PBL Netherlands Environmental Assessment Agency, The Hague.

Thiffault E, Béchard A, Paré D, Allen D (2014) Recovery rate of harvest residues for bioenergy in boreal and temperate forests: A review. WIREs Energy Environ.

Thompson JL, Tyner WE (2014) Corn stover for bioenergy production: cost estimates and farmer supply response. Biomass and Bioenergy, 62, 166-173.

USDA (1997) Predicting Rainfall Erosion by Water: A Guide to Conservation Planning with the Revised Universal Soil Loss Equation (RULSE) (No. Agricultural Handbook 703). United States Department of Agriculture, Washington, DC.

USDE (2011) U.S. Billion-Ton Update: Biomass Supply for a Bioenergy and Bioproducts Industry. Oak Ridge National Laboratory, Oak Ridge, TN.

van Vuuren DP, Bellevrat E, Kitous A, Isaac M (2010) Bio-energy use and low stabilization scenarios. The Energy Journal, 31(Suppl. 1), 193-221.

van Vuuren DP, Kriegler E, O'Neill B et al. (2014) A new scenario framework for climate change research: scenario matrix architecture. Climatic Change, 122, 373-386.

WHO (2011) Global Database of Household Air Pollution Measurements [Online] Available at: http://www.who.int/indoorair/health_impacts/databases_iap/en/ (accessed 10 December 2014)

Wicke B, van der Hilst F, Daioglou V et al. (2014) Model collaboration for the improved assessment of biomass supply, demand, and impacts. GCB Bioenergy, 7, 422-437.

Xu X, Fu Y, Li S (2013) Spatiotemporal changes in crop residues with potential for bioenergy use in China from 1990 to 2010. Energies, 6, 6153-6169.

Yamamoto H, Fujino J, Yamaji K (2001) Evaluation of bioenergy potential with a multi-regional gloabla-land-use-and-energy model. Biomass and Bioenergy, 21, 185-203.

\section{Supporting Information}

Additional Supporting Information may be found in the online version of this article:

Table S1 Projections of global population, GDP per capital, agricultural production and wood production.

Table S2 Theoretical, ecological and available potential of residues $\left(\mathrm{EJ} \mathrm{yr}^{-1}\right)$.

Table S3 Global residue potentials (EJ $\mathrm{yr}^{-1}$ ) for all reference scenarios for 2050 and 2100 .

Table S4 Cumulative available residues $\left(\mathrm{EJ} \mathrm{yr}^{-1}\right)$ for increasing supply cost 